\title{
Efectos del tratamiento periodístico sesgado ideológicamente en el procesamiento cognitivo de información política. Un abordaje experimental
}

\author{
Ana Pamela Paz García ${ }^{1}$ (id) \\ Silvina Brussino 2 \\ Daniela Alonso 3
}

\begin{abstract}
Reconociendo las condiciones de polarización del mercado mediático actual, se abordan características salientes del procesamiento cognitivo de información política textual de importancia coyuntural (noticias de prensa reales de fuentes ideológicas contrastantes). Aplicando un diseño experimental inter-sujetos de grupos aleatorios (con una variable independiente que asume cuatro niveles) sin grupo control, se analizan los efectos del tratamiento periodístico sesgado ideológicamente sobre el procesamiento informativo de audiencias locales y se valora el rol modulador de las variables necesidad de cognición y auto-posicionamiento ideológico. Entre los resultados principales, se confirma un patrón pro-actitudinal y un mayor tiempo de exposición ante fuentes no familiares, junto a una conexión entre percepción de sesgo, valoración del tema y opinión sobre la fuente variable en función del autoposicionamiento, entre otros factores que evidencian una lógica selectiva de consumo auto-referente y defensivo.
\end{abstract}

Palabras clave: información política; selectividad mediática; ideología política; consumo; Argentina

\section{Introducción}

En la actualidad, el estudio de los efectos mediáticos en el campo de la comunicación política desplaza su interés hacia "qué hace la gente con los medios" (Shah et al., 2017; Valkenburg, Peter y Walther, 2016), enfocando aspectos cognitivos, emocionales e ideológicos del consumo informativo. En este marco, se destacan fenómenos de auto-comunicación masiva o de-masificación, donde las audiencias personalizan

\footnotetext{
${ }^{1}$ Equipo de Psicología Política - IIPsi, Universidad Nacional de Córdoba (UNC) y Conicet. Córdoba (Córdoba), Argentina. E-mail: <pamela.pazgarcia@conicet.gov.ar>.

2 Equipo de Psicología Política - IIPsi, Universidad Nacional de Córdoba (UNC) y Conicet. Córdoba (Córdoba), Argentina. E-mail: <silvina.brussino@unc.edu.ar>.

${ }^{3}$ Equipo de Psicología Política - IIPsi, Universidad Nacional de Córdoba (UNC) y Conicet. Córdoba (Córdoba), Argentina. E-mail: <dalonso@unc.edu.ar>.
} 
mensajes pero también son moldeadas por su propio uso selectivo de medios y tecnologías. Atendiendo a estos cambios, en un contexto local de discusión pública sobre la concentración del mercado mass-mediático y su impacto en la calidad de la política democrática en Argentina habilitado a partir de la Ley no 26.522, esta investigación aborda características salientes del procesamiento informativo en torno al eje objetividad-sesgo en noticias reales, bajo tratamientos periodísticos editorialmente en conflicto dentro de dicha coyuntura.

Al respecto, dicho objetivo de investigación se considera de relevancia específica en dos sentidos. Primero, en cuanto al aporte al estudio situado de los efectos mediáticos, contextualizando las direcciones de la percepción de sesgo en el marco de valoraciones y actitudes de las audiencias que dan cuenta de una percepción sesgada, en tanto experiencia más profunda. Aquí se reconoce la vigencia de un esquema de "selectividad motivada" (Barnidge et al., 2020) en torno al procesamiento de fuentes y contenidos, considerando que las audiencias tienden a percibir sesgada la cobertura mediática en general, incorporando reacciones de hostilidad (Gunther y Chia, 2001) cuanto más comprometido ideológica y cognitivamente es su consumo. Segundo y en cuanto al empleo de la lógica experimental para evaluar relaciones explicativas entre variables aportadas por los antecedentes, se destaca el esfuerzo por construir un diseño que refleje ciertas condiciones exógenas que modelan el procesamiento informativo, empleando noticias reales polarizadas dentro de la agenda política vigente.

Considerando la discusión sobre las influencias mediáticas en las actitudes políticas en el marco de procesos masivos, cabe advertir el todavía incipiente empleo de técnicas experimentales. En contraste, diversos autores coinciden en reconocerle al menos tres ventajas (McDermott, 2002; Druckman et al., 2006; Morton y Williams, 2006): 1) capacidad metodológica para identificar y demostrar relaciones de causa-efecto; 2) apoyo al desarrollo teórico, en relación colaborativa con modelos formales; 3) fomento de la pluralidad analítica, donde la investigación experimental como parte integral de la política de innovación habilitaría que la sociedad obtuviera conocimiento confiable sobre las consecuencias del cambio social, político o económico (Campbell, en Druckman et. al, 2006).

A continuación, en tres secciones específicas de este apartado introductorio, se abordarán una serie de antecedentes que dan sustento a los objetivos y las hipótesis propuestas. Primero y con relación al fenómeno de selectividad motivada, observable empíricamente en las audiencias mediáticas contemporáneas, se destaca el proceso de "hostilidad mediática" y sus efectos en el procesamiento sesgado de contenidos informativos. Se trata de procesos y efectos particularmente atendidos por la literatura especializada en el abordaje experimental del consumo político-informativo. Segundo y como aporte distintivo de la línea de trabajo en torno a la presente investigación, se profundiza en el papel de la ideología política en el procesamiento sesgado de etiquetas y fuentes informativas. Por último y en tercer lugar, se incluyen otras variables vinculadas a 
dicho procesamiento en términos cognitivos, valorando el tiempo de lectura, el nivel de comprensión y la atribución de interés e importancia a las noticias periodísticas, entre otras actitudes vinculadas al tratamiento informativo sesgado ideológicamente percibido por los/as consumidores/as.

Procesos y efectos de selectividad motivada. Sesgos percibidos y percepciones sesgadas

En el contexto de polarización político-ideológica e hiper-fragmentación mediática que caracteriza a las democracias contemporáneas, se observa que la teoría del malestar mediático 4 (media malaise) recupera vigencia y el concepto de "selectividad" de las audiencias se complejiza. Mientras la búsqueda de reducción de la disonancia cognitiva se convierte en un motivo relativamente débil para la adquisición de información (Iyengar y Hahn, 2009), las audiencias desarrollan consumos selectivos como respuesta necesaria ante medios crecientemente radicalizados bajo diferentes orientaciones políticoideológicas. Con frecuencia los sesgos informativos son atribuidos por las audiencias a grandes medios y cadenas bajo un patrón de acercamiento / evasión variable en función del tema principal de las noticias. En tales condiciones las personas tienden a percibir sesgos en la cobertura mediática política, aun cuando ésta hubiera sido producida siguiendo códigos de objetividad y normas de reporte periodístico balanceado (Barnidge et al., 2020; Arceneaux, Johnson y Chad, 2012).

En este marco, se destaca la emergencia de procesos de "hostilidad mediática", en tanto efectos que complejizan el abordaje del procesamiento informativo de tipo cognitivo. Su estudio surge en los años 80, con las investigaciones de Vallone, Ross y Lepper (1985) sobre la percepción de sesgo contrario a la propia posición en grupos polarizados, expuestos a idénticas noticias balanceadas en términos informativos. Estudios recientes extienden el análisis de este fenómeno a la exposición directa a noticias sesgadas (relative hostile media effect - HME) sin estímulo neutral, profundizando en mecanismos y efectos del procesamiento sesgado. Al respecto, se han analizado el recuerdo y la caracterización selectiva de mensajes que involucran reacciones emocionales (Matthes, 2011), los efectos de contraste y asimilación producto del razonamiento motivado de audiencias específicas en contextos específicos (Gunther, 2017) como procesos electorales (Bachl, 2016), así como los fenómenos de ignorancia pluralista, proyección de falsos consensos (Gunther y Chia, 2001) o efecto de tercera persona (Davison, en Gomes, 2016), entre otros temas relacionados.

En entornos mediáticos caracterizados por una expansión de ofertas de entretenimiento junto a una reducción de las audiencias interesadas en contenidos

\footnotetext{
4 Tanto los supuestos de la teoría del malestar mediático como las tesis opuestas en torno a la movilización cognitiva han sido contrastadas empíricamente en el contexto de la realidad política norteamericana. En la actualidad el debate continúa y diferentes coyunturas objeto de investigaciones fuera de EE.UU. (Jorge y Miró, 2011) permiten reconocer, al respecto, posturas no excluyentes.
} 
informativos, cabe además preguntarse si, ante la tendencia a la proliferación de noticias orientadas ideológicamente, el comportamiento defensivo y auto-referente de los consumidores podría afectar la calidad democrática. Expertos argumentan que la polarización política disminuye el impacto de información sustantiva, estimulando una mayor confianza en opiniones sustantivamente menos fundadas (Druckman, Peterson y Slothuus, 2013). Tales procesos afectarían la cultura política en general, dado que la disposición a enfocarse en lo agradable/placentero representa una "respuesta subjetivamente racional" en un ambiente mediático que poco alimenta "procesos de formación de opinión inspirados en ideales democráticos" (Knobloch-Westerwick y Meng, 2009 , p. 446). En contrapartida, en estudios sobre las actitudes hacia temas de política pública, se ha verificado el efecto estadísticamente significativo de la información en las actitudes, reconociendo su impacto en la política democrática (Turgeon y Rennó, 2010): mientras el nivel de escolaridad y el conocimiento político no mostraron efectos claros, el volumen de información pudo relacionarse con el cambio de opinión, destacando el impacto de una ciudadanía informada.

El papel de la ideología política. Actitudes de las audiencias mediáticas en interacción con fuentes, etiquetas y tratamientos periodísticos de la información política

Como se ha enfatizado previamente, la percepción de sesgo en las audiencias contemporáneas no solo tendría relación con procesos externos como la polarización político-ideológica del mercado mediático-informativo. Subyacen a estas actitudes condiciones inter-subjetivas y endógenas derivadas de factores cognitivos y motivacionales que alimentan los comportamientos selectivos. Iyengar y Hahn (2009) observan que los consumidores tienden a ignorar los reportes noticiosos anónimos, buscando pistas ideológicas en contenidos y fuentes. En la misma línea, y procurando esclarecer los mecanismos cognitivos del procesamiento informativo, Feldman $(2008,2011)$ estudia el papel de las "noticias opinadas" (opinionated news). Sus hallazgos conectan con los resultados antes señalados, al encontrar que las personas fallan en reconocer los sesgos de cobertura mediática congruentes con sus actitudes previas, mientras el dispositivo periodístico de la "objetividad"5 se convierte en un valor incorporado a sus expectativas informativas como indicación de credibilidad y confianza. En este esquema actitudinal influenciado por elementos normativos (objetividad) y marcos sociales (ideología), el procesamiento sesgado se muestra contingente con respuestas afectivas dialogando con la hipótesis de la selectividad mediática oposicional (Arceneaux, Johnson y Chad, 2012). Mientras la desconfianza en los medios masivos diluye sus efectos e incrementa el peso de

\footnotetext{
${ }^{5}$ La consideración de la objetividad como pretensión de neutralidad corresponde a una dimensión valorativa mediadora de los procesos de producción y recepción de la información política en el campo periodístico. Se trata de una condición que valida discursos hegemónicos (Biroli y Miguel, 2012), legitimando específicas ideologías y ontologías del mundo social y político respecto de las cuales con frecuencia las audiencias masivas se encuentran en condiciones de dependencia cognitiva.
} 
la exposición selectiva (Feldman, 2008), las "noticias opinadas" en comparación con las de apariencia neutral generan con mayor frecuencia un procesamiento negativo de su fuente.

Por otro lado, el sesgo de contenido percibido varía en función de la fuerza de las señales políticas en la noticia, mientras el sesgo percibido en la fuente es más "una función de las características del receptor" (Feldman, 2011, p. 426). Cabe puntualizar aquí que los efectos de la información en el procesamiento cognitivo de las audiencias se comprenden en profundidad contextualizándolos, dentro de la coyuntura político-discursiva en que se generan. Cuando la audiencia está polarizada las "noticias opinadas" se producen para el mercado y la exposición pronunciada a la cobertura noticiosa de un extremo ideológico favorece un "efecto caja de resonancia" (Iyengar y Hahn, 2009, p. 35), tendiendo a reforzar actitudes pre-existentes. En este escenario, la exposición selectiva se torna un comportamiento cotidiano altamente probable, además de funcional desde la perspectiva del razonamiento políticamente motivado. En su análisis sobre la consistencia de las actitudes de las audiencias en torno a tópicos, Knobloch-Westerwick y Meng (2009) encuentran que el patrón de exposición pro-actitudinal (attitude-consistent) predomina con independencia del tema noticioso, fomentado entre otros factores por una alta frecuencia cotidiana de consumo. En la misma línea, Arceneaux, Johnson y Chad (2012) destacan que las personas forzadas a ver noticias ideológicamente discordantes tienden a juzgar a los medios masivos como menos confiables, en contraste con participantes expuestos a contenidos ideológicamente consistentes.

En el marco de (des)confianza en que los consumidores incorporan pistas de hostilidad, los autores puntualizan dos flujos de negatividad hacia las noticias mediáticas: por una parte, desde la perspectiva ofrecida por la propia fuente, y por otra, derivada de pistas que ésta comunica sobre sus colegas en la industria noticiosa. Tanto en la investigación pionera de Vallone, Ross y Lepper (1985) como en estudios posteriores (Gunther y Chia, 2001), la observación de efectos de hostilidad se verifica ante productos de tratamiento periodístico específicamente. Expertos han demostrado que ante la exposición de audiencias a los mismos materiales bajo otro género (por ej., ensayo estudiantil) se diluyen los efectos de hostilidad (Gunther y Liebhart; y Gunther y Schmitt, en Gomes, 2016). Aquí, Gomes (2016) puntualiza la relevancia de la valoración de la fuente, como base cognitiva para el desarrollo actitudinal de la hostilidad y la proyección de impacto en la opinión pública por parte de las audiencias.

En este punto el concepto de "selectividad motivada" opera reconociendo el interjuego contextual y recíproco entre la oferta y demanda de contenidos mediáticoinformativos, destacándose el papel de etiquetas y encuadres ideológicos en el procesamiento de las audiencias. Por un lado, se observa cómo los consumidores tienden a adoptar las etiquetas ideológicas adjudicadas a las fuentes informativas como pistas de la mayor relevancia. Así, estos dispositivos heurísticos resultan efectivos atajos cognitivos en la medida en que el tema sea más difícil (Merolla, Stephenson y Zechmeister, 2007), regulando el interés de las personas en los contenidos noticiosos. Por otro lado, junto al 
interés por ciertos temas políticos, el auto-posicionamiento ideológico influye significativamente en el carácter de sus elecciones noticiosas (Iyengar y Hahn, 2009). Al respecto, López Sáez y Martínez Rubio (2005) estudian el papel mediador de la ideología política en la credibilidad otorgada a ciertas fuentes, observando que el autoposicionamiento modula la valoración de fuentes y mensajes, en tanto anclaje cognitivo del procesamiento informativo. Estos autores advierten una mayor credibilidad otorgada a fuentes noticiosas oficiales a medida que la ideología de las audiencias se desplaza a la derecha y un efecto inverso ante fuentes extra-oficiales, ante versiones noticiosas opuestas y en ciudadanos auto-posicionados hacia la izquierda. Bajo esta línea, Brussino et al., (2011) encuentran en la ideología política un método heurístico anticipatorio de las decisiones de exposición de las audiencias. Aun cuando la ideología política no es verbalizada como razón explícita de sus preferencias, se advierten mecanismos de exposición selectiva ideológicamente motivada bajo condiciones coincidentes con Iyengar y Hahn (2009), en cuanto al grado de diversificación de la dieta informativa de conservadores y progresistas. Mientras las personas de centro y derecha consumen exclusivamente medios que identifican como de centro o derecha, aquellas identificadas con posiciones progresistas muestran consumos más heterogéneos (Brussino et al., 2011), no restringidos a posturas coincidentes e incluyendo medios etiquetados como de centro y derecha.

\section{Otras variables vinculadas al procesamiento cognitivo de información política}

En la línea de estudios desarrollados bajo la hipótesis HME relativa (relative hostile media effect) ${ }^{6}$, Gunther (2017) destaca el tiempo de lectura, observando que las audiencias emplean mayor tiempo o presentan una mayor demora en el procesamiento de información sesgada de contenido contra-actitudinal o desagradable. Respecto de los mecanismos cognitivos subyacentes a esta tendencia, se han enfocado tanto el ejercicio de contra-argumentación mental que podría desarrollar el lector, como la mayor lentitud en procesar contenidos menos familiares. En la misma línea, se ha observado que en la recepción de noticias de prensa bajo tratamientos periodísticos específicos sin fuente explícitamente identificada (Ariyanto, Hornsey y Gallois, en Gomes, 2016), los participantes no logran concluir con certeza cuál es la orientación político-ideológica de la información. Se trataría de la pérdida del poder heurístico aportado por las etiquetas ideológicas, en tanto recurso cognitivo abordado en los antecedentes reportados.

\footnotetext{
${ }^{6}$ Aquí nos ubicamos en línea con evidencias sobre la tendencia a evaluar contenido contra-actitudinal como sesgado y hostil por parte de audiencias cognitivamente más involucradas (posicionadas e interesadas en temas específicos), aún ante noticias balanceadas en términos de presentación de una cobertura neutral (Gunther, Liebhart y Chia en Matthes, 2011). Bajo la HME relativa, esta reacción de hostilidad emerge ante dos pre-condiciones: fuentes valoradas como periodísticas - excluyente - e influyentes en la opinión pública - desde la valoración de las audiencias sobre la importancia general de tales contenidos.
} 
En cuanto a la comprensión del contenido noticioso, excediendo los antecedentes provenientes del campo de la experimentación en comunicación política y desde una perspectiva comunicológica, el concepto de foco editorial emerge como clave de recuperación de los contenidos centrales en la información del género periodístico. Así, este concepto alude a "una frase construida por el editor y su periodista que guía la elaboración de un trabajo informativo y sintetiza la idea central de éste, de manera que la información pueda ser más fácilmente reconstruida por los espectadores" (Liepins, Porath y Puente, 2010, p. 51). Dentro de esta línea de reflexión integrada sobre los procesos de producción y consumo informativo, Lang et al. (citado por Liepins, Porath y Puente, 2010) sostienen que las características de edición del mensaje pueden afectar su comprensión. Aquí se destaca además la necesidad de cognición (NFC, por sus siglas en inglés), en tanto tendencia personal a disfrutar de un procesamiento informativo esforzado. Esta variable se ha relacionado tanto con la alta motivación para procesar mensajes y argumentos en personas cognitivamente más involucradas (Matthes, 2011), como con el consumo de dietas más heterogéneas en términos ideológicos evidenciado por personas con mayor necesidad de cognición positiva (Knobloch-Westerwick; Krcmar; y Oliver y Krakowiak, en Valkenburg, Peter y Walther, 2016).

Finalmente cabe reconocer diferentes valores noticia en la evaluación de las audiencias, significativos también desde el punto de vista del mercado periodístico. Así, el interés por el tema se ha asociado con características específicas del texto procesado (Schiefele y Krapp, 1996; Schiefele, 1990), favoreciendo el aprendizaje, la comprensión y la recordación de la información ofrecida. De este modo la noticia puede resultar valorada por el lector en dimensiones de interés tales como su utilidad, carácter estimulante, significativo o importante, etc. Particularmente la importancia para el propio lector o para la opinión pública en general, se trata de una característica relacionada con el grado de involucramiento de las audiencias con la información receptada, junto a otros factores no abordados en esta investigación tales como el activismo o el conocimiento político. Siguiendo a Matthes (2011), a mayor involucramiento de los receptores en alguna de estas dimensiones, mayor resulta su percepción de sesgo y hostilidad. En cuanto al vínculo entre importancia personal y pública, desde teorías perceptuales, motivacionales y cognitivas en torno al procesamiento informativo se destaca el efecto de proyección - abordado también en los antecedentes (Gunther y Chia, 2001) -, en tanto tendencia a sobre-estimar la prevalencia de las propias actitudes en la población general. También llamado efecto de tercera persona (Gomes, 2016), implica la asunción de una influencia persuasiva de la prensa en la opinión pública en la dirección de la propia opinión.

\section{Objetivo e hipótesis}

Reconociendo entonces un escenario local de polarización ideológica entre perspectivas editoriales sobre una misma temática, el objetivo es analizar los efectos del 
tratamiento periodístico sesgado ideológicamente sobre los mecanismos cognitivos de procesamiento informativo de las audiencias (tiempo de lectura, percepción de sesgo ideológico, nivel de comprensión noticiosa, valoración del tratamiento informativo del tema y opinión sobre la fuente). Asimismo, se propone valorar el rol modulador de las variables actitudinales necesidad de cognición y el auto-posicionamiento ideológico sobre los efectos del tratamiento periodístico sesgado ideológicamente. En este marco, se formulan las siguientes hipótesis de investigación:

H1: El tratamiento periodístico sesgado ideológicamente por la fuente (izquierda y derecha), identificada y no identificada, influye sobre el procesamiento cognitivo de la noticia (tiempo de lectura, percepción de sesgo ideológico, nivel de comprensión noticiosa, valoración del tratamiento informativo del tema y opinión sobre la fuente).

H1a. En el procesamiento cognitivo de noticias discordantes con la propia posición ideológica, las personas emplean mayor tiempo de lectura.

H1b. En el procesamiento cognitivo de noticias discordantes con la propia posición ideológica, las personas tienden a valorar su fuente como menos creíble/confiable/objetiva.

H2: El auto posicionamiento ideológico modula los efectos del tratamiento periodístico sesgado ideológicamente por la fuente (izquierda y derecha) sobre las variables de procesamiento cognitivo de la noticia.

H3: La necesidad de cognición modula los efectos del tratamiento periodístico sesgado ideológicamente por la fuente (izquierda y derecha) sobre las variables de procesamiento cognitivo de la noticia.

\section{Método}

\section{Diseño y participantes}

Se aplicó un diseño experimental inter-sujetos de grupos aleatorios donde cada tratamiento fue administrado a un grupo distinto de participantes (con una variable independiente que asume distintos niveles). En este caso, no se contaba con grupo control dado que, en este escenario, no era factible incluir una noticia política e ideológicamente neutra. Así, se conformaron cuatro grupos experimentales en función de la manipulación de la variable independiente tratamiento periodístico sesgado ideológicamente por la fuente (izquierda y derecha), con fuente identificada y no identificada (en adelante VI): Grupo 1 "noticia La Voz del Interior (LV) derecha-identificada", Grupo 2 "noticia Página 12 (P12) izquierda-identificada", Grupo 3 "noticia LV derecha-anonimizada" y Grupo 4 "noticia P12 izquierda-anonimizada". Los efectos de dicha VI se infieren "comparando las medias obtenidas en las variables dependientes por diferentes grupos de sujetos" (Balluerka y 
Vergara, 2002, p. 22). Participaron voluntariamente 48 estudiantes de la Facultad de Psicología (Universidad Nacional de Córdoba), que se asignaron de manera aleatoria a cada condición experimental. En la Tabla 1 se observa su distribución en términos de género y edad:

Tabla 1

Edad y género de participantes por grupo experimental

\begin{tabular}{|l|c|c|c|c|}
\hline & \multicolumn{2}{|c|}{ Noticias identificadas } & \multicolumn{2}{c|}{ Noticias anonimizadas } \\
\hline & Grupo 1 (LV) & Grupo 2 (P12) & Grupo 3 (LV) & Grupo 4 (P12) \\
\hline Mujeres & $24.29+-2.43(6)$ & $25.43+-5.68(6)$ & $25.67+-3.67(6)$ & $27.13+-2.90(6)$ \\
\hline Hombres & $23.50+-2.88(6)$ & $24.83+-2.13(6)$ & $23.50+-2.66(6)$ & $27.83+-7.08(6)$ \\
\hline
\end{tabular}

Fuente: Elaboración propia.

Nota: El primer número de cada celda indica media \pm DE de edad; entre paréntesis se indica la cantidad de participantes.

En primera instancia, para determinar el sesgo ideológico de la fuente en cuanto al tratamiento periodístico de la noticia y poder generar los distintos niveles de la VI se realizó un seguimiento de cobertura mediática durante dos semanas previas al trabajo de campo, identificando las temáticas priorizadas en la agenda periodística local. Además, se solicitó a cuatro expertos su juicio sobre el posicionamiento ideológico (izquierda-derecha) de cinco titulares noticiosos publicados dentro del período por los principales diarios nacionales y locales circulantes en Córdoba. Así, con el cien por ciento de acuerdo entre los jueces, se seleccionaron dos fuentes del mismo acontecimiento noticioso, consistentemente opuestas en términos ideológico-editoriales. La noticia seleccionada fue el conflicto entre el Gobierno nacional y el multimedio Grupo Clarín por la puesta en vigencia de la Ley de Servicios de Comunicación Audiovisual n² 26522 como temática de máxima relevancia en la agenda local. Una correspondía al diario LV (diario local de mayor posicionamiento, orientación opositora "pro Clarín" ideológicamente ubicado a la derecha por los expertos y otra de $P 12$ (de menor alcance, aunque de importante consumo entre estudiantes universitarios, población objetivo del estudio), identificada como oficialista "pro Gobierno" (ubicada ideológicamente a la izquierda) ${ }^{7}$. Asimismo, se manipuló el etiquetamiento de la fuente, generando el nivel fuente ideológicamente sesgada identificada y anónima.

Finalmente y a los fines de aportar información contextual sobre las noticias seleccionadas, entre 2009 y 2014, período coincidente con el trabajo de campo de esta

\footnotetext{
7 Se detallan aquí las direcciones URL de ambas noticias en su estado original de publicación: "En su aniversario, El Cronista pidió por la libertad de expresión" (La Voz del Interior, 1/11/2012), <http://www.lavoz.com.ar/noticias/politica/su-aniversario-cronista-pidio-libertad-expresion>; "Están desafiando a la democracia" (P12, 1/11/2012), <http://www.pagina12.com.ar/ diario/elpais/subnotas/161025-2012-11-01.html>. Sobre la consideración de ambas noticias como estímulos reales de tratamiento periodístico sesgado ideológicamente, este criterio se sustenta en antecedentes locales específicos (Di Paolo, 2017; Ingrassia, 2016; Flax, 2013) en torno al contraste de su desempeño informativo ante temas políticos de importancia coyuntural tales como el debate público de la Ley $n^{\circ} 26.522$.
} 
investigación, observamos que en Argentina se produce una fuerte confrontación entre la presidencia de Cristina Fernández de Kirchner y el Grupo Clarín, multimedio líder del mercado nacional y regional. En el marco de las elecciones legislativas de 2009 que marcaron la primera derrota electoral del kirchnerismo (Kitzberger, en Balán, 2013), el gobierno impulsa una nueva ley de medios audiovisuales - Ley no 26.522 de Servicios de Comunicación Audiovisual, sancionada por el Congreso en octubre de 2009. Mientras para algunos sectores se trataba de una ley "mordaza" que afectaría la libertad de expresión del periodismo y comprometía a los licenciatarios actuales del sistema de radiodifusión entre quienes el multimedios Clarín ocupaba una posición dominante -, desde sectores oficialistas enfatizaban objetivos de des-monopolización y fomento de la competencia (Paz García, Sgró Ruata y Guzmán, 2013) tendientes a la construcción de una oferta más amplia para la ciudadanía. Desde entonces se instala un contexto de polarización mediática cuya característica clave, además de la conflictividad discursiva, ha sido la "homogeneidad" de los medios en contraposición. En la prensa argentina, esta homogeneidad es posible dada la "falta de separación (pared invisible) entre las opiniones editoriales y las columnas de noticias" (Balán, 2013, p. 477) que configura las coberturas informativas, afectando no solo el contenido sino también el tono y espacio otorgado por los diferentes medios masivos a ciertas noticias políticas.

\section{Procedimiento}

Las sesiones experimentales fueron individuales. En primer lugar, las personas participantes respondieron un cuestionario administrado por una misma entrevistadora que registraba las respuestas sobre variables actitudinales como necesidad de cognición y autoposicionamiento ideológico, con miras a considerar su efecto modulador respecto de la experiencia de exposición noticiosa. Posteriormente, se le presentaban 4 sobres cerrados que contenían, en cada uno de ellos una noticia según las 4 condiciones experimentales (Grupo 1, Grupo 2, Grupo 3 y Grupo 4) previamente descriptas, y debía elegir uno. Cabe señalar que las noticias estaban igualadas en cuanto al formato de edición (tipo de papel, tipo de letra, diagramación, etc.). Se les entregaba el sobre con la noticia seleccionada, con la consigna de conversar a posteriori sobre las impresiones personales sobre la lectura del material. Una vez que comenzaba con la lectura de la noticia, la entrevistadora cronometraba y registraba el tiempo de lectura que la noticia insumía y, en una fase posterior, se administraba un cuestionario correspondiente a las variables dependientes (percepción de sesgo, tipo de sesgo percibido, valoración del tratamiento informativo del tema y opinión sobre la fuente de la noticia), aplicando finalmente una entrevista semiestructurada para evaluar el nivel de comprensión noticiosa de las personas. 


\section{Instrumentos}

Además de la VI tratamiento periodístico sesgado ideológicamente, en cada sesión experimental se incluyeron respectivamente las siguientes variables dependientes (VD), considerando al auto-posicionamiento ideológico y la necesidad de cognición como variables moduladoras.

\section{Variables dependientes}

Tiempo de lectura: se cronometró el tiempo total insumido por cada participante en la lectura de la noticia, como medida comparativa de interés en los estudios de exposición selectiva (Knobloch et al., 2003; Knobloch-Westerwick y Meng, 2009).

Nivel de comprensión noticiosa: para el registro de esta variable se realizó un ejercicio de recordación "guiada" sobre el texto noticioso, mediante el planteo de los siguientes interrogantes abiertos: "¿de qué se trata la noticia?; ¿a qué problema político se refiere la noticia?; ¿se mencionan causas o consecuencias?, en caso afirmativo ¿cuáles causas? ¿cuáles consecuencias?; ¿se mencionan protagonistas?, en caso afirmativo ¿cuáles?". Con posterioridad, las respuestas espontáneas fueron codificadas aplicando un ranking de puntuaciones siguiendo la "Escala de Comprensión de Noticias", de Robinson y Levy (en Liepins, Porath y Puente, 2010), basada en el papel del foco editorial en la comprensión noticiosa. Para contar con un criterio de validación externa del foco editorial de cada noticia, dado que se trata de una escala aplicada mediante la evaluación cualitativa y posterior puntuación asignada por las investigadoras a las respuestas abiertas de las personas, se utilizó un juicio de expertos. Para ello, se brindó a un grupo de jueces colaboradores una definición de foco editorial ${ }^{8}$ y se les solicitó identificar dicho elemento retórico dentro de cada noticia. Como resultado de esta prueba se observó cien por ciento de acuerdo entre los cuatro jueces consultados en torno a la definición del foco editorial de cada noticia estímulo empleada, aportando validez interna. Así, la puntuación de la variable incluyó las siguientes categorías: 0 = no responde nada o responde de modo erróneo, $1=$ recuerda el tema general de la noticia, 2 = recuerda el tema general y menciona un detalle de la noticia (vaga recordación), 3 = menciona una idea específica contenida en la noticia pero no su tema principal ni menciona foco editorial, 4 = recuerda el tema principal de la noticia pero tampoco menciona foco editorial (recordación específica), 5 = menciona el foco editorial de la noticia (idea fuerza del artículo), 6 = menciona el foco editorial y un detalle, 7 = menciona el foco editorial y dos detalles, $8=$ menciona el foco editorial y tres o más detalles.

\footnotetext{
${ }^{8}$ En este sentido y con base en la literatura específica sobre el tema, se conceptualizó el foco editorial como aquella idea fuerza que le confiere una intención específica al proceso de narración. En esta línea, para la presente investigación se trata de una frase construida por el editor y/o periodista que guía el proceso de producción de su trabajo informativo con relación al público lector, sintetizando una idea central que estructurará tanto el relato noticioso como su tratamiento informativo.
} 
Percepción de sesgo ideológico: se evaluó a través de dos afirmaciones complementarias respecto de las cuales las personas debían indicar su grado de acuerdo en una escala tipo Likert de 5 puntos, consignando si la información recibida era objetiva y si tenía sesgo ideológico-político $(r=.67 ; \mathrm{p}=.000)$.

Tipo de sesgo percibido: se evaluó a partir de una pregunta abierta administrada a los participantes que señalaron haber percibido sesgo en la información. Posteriormente, dichas respuestas espontáneas fueron codificadas en términos de la dicotomía "sesgo oficialista" o "sesgo opositor".

Valoración del tratamiento informativo del tema: adoptando como referencia las escalas "Evaluation of the articles' news value" (Knobloch et al., 2003) e "Impressions of the articles" (Knobloch et al., 2003), en una escala de 5 puntos (desde 1 = nada a 5 = muy), se pidió a las personas que evaluaran la presencia de ocho valores-noticia: utilidad, interés, sensacionalismo, credibilidad, preocupación e importancia para sí mismo y para el público en general. Esta última diferenciación derivó de la prueba piloto del cuestionario, donde se observó que ambas valoraciones son efectivamente diferenciales, en línea con una tendencia individual a sobre-estimar la propia capacidad de resistencia (Fara, 2005) ante los efectos de la influencia mediática en la opinión pública. Asimismo, cada valor-noticia fue considerado de modo independiente en el análisis.

Opinión sobre la fuente: se registró la valoración sobre la fuente con relación a cinco atributos: brinda información confiable, ofrece información actualizada, quién/es escribe/n resulta/n creíble/s, aporta datos para pensar el tema, no aporta nada nuevo. Todas las respuestas fueron nuevamente registradas en una escala de 5 puntos entre (1) "para nada" y (5) "muy". Al igual que en la "valoración del tratamiento...", se consideró cada dimensión de modo independiente.

\section{Variables moduladoras}

Auto-posicionamiento ideológico: se pidió a las personas auto-identificarse ideológicamente en un rango desde (1) "Totalmente de izquierda" a (7) "Totalmente de derecha", siendo el (4) equivalente a la opción "Centro". También se contemplaron las opciones "No puede auto-ubicarse" y "Ninguna" junto a las categorías alternativas "Apolítico/a" e "Independiente"9. Los puntajes fueron recategorizados en izquierda (1 a 3), centro (4) y derecha (5 a 7).

Necesidad de cognición (positiva y negativa): para evaluar este aspecto se aplicó la versión en español (Falces et al., 2001) de la escala de necesidad de cognición (escala NC) originalmente propuesta por Petty y Cacioppo en 1986 (Need for Cognition Scale). El índice

\footnotetext{
${ }^{9}$ Con el término "apolíticos" se indican aquellos sectores de la población que combinan una desvinculación respecto de dicho sistema con un desinterés por la dinámica política, mientras los "independientes" representan a "quiénes, a pesar de no estar identificados partidariamente, tienen interés por la política y poseen los recursos socio-económicos mínimos que permiten un involucramiento y comprensión de la dinámica política" (Vaggione y Brussino, 1997).
} 
de fiabilidad alfa de Cronbach para la dimensión de baja NC o sub-escala negativa fue de .73 , mientras para la dimensión de alta NC o sub-escala positiva fue de .71.

\section{Análisis de datos}

Como primer paso, se analizó la existencia de los supuestos de normalidad y homocedasticidad, teniendo en cuenta que la condición de muestras independientes ya había sido observada, como regla de selección de los casos en la configuración del propio diseño experimental. Se contrastó la hipótesis de igualdad de varianzas, encontrando la existencia de diferencias significativas $(p<.050)$ en las variables necesidad de cognición negativa, percepción de sesgo ideológico, tipo de sesgo percibido y opinión sobre el tratamiento periodístico (dimensión de "significación"). Ante esta situación y si bien la literatura admite la posibilidad de cierto alejamiento del supuesto de normalidad (Barón López y Téllez Montiel, 2004), en lugar de la prueba de Levene se emplearon las pruebas robustas de Welch y Brown-Forsythe (basadas en una distribución asintótica del estadístico F) a fin de decidir sobre el siguiente paso clave: la hipótesis de igualdad de medias poblacionales. Atendiendo a estos nuevos resultados, se verificó la existencia de diferencias inter-grupales significativas en el tiempo de lectura y las opiniones sobre la credibilidad del artículo y confiabilidad de la fuente. Profundizando en estas diferencias, luego se revisan los valores del método Games-Howell de estudio de contrastes post hoc, en tanto solución final adecuada para la comparación inter-grupal de medias, ante la imposibilidad de asumir varianzas poblacionales iguales ${ }^{10}$.

Luego, para conocer el efecto de la VI tratamiento periodístico sesgado ideológicamente sobre las VD (tiempo de lectura, percepción de sesgo ideológico, tipo de sesgo percibido, valoración del tratamiento informativo del tema y opinión sobre la fuente), se realizaron análisis de la varianza de un factor (ANOVA). Adicionalmente, en los casos que se registraron diferencias entre grupos y con el objetivo de conocer qué medias difieren significativamente entre sí, se realizaron comparaciones post hoc utilizando el estadístico de Bonferroni con una probabilidad de error tipo I fijada en $<, 05$. Además, se estimaron análisis de covarianza (ANCOVA) que nos permitieron controlar el rol de dos variables (VC) no incluidas en el tratamiento experimental: necesidad de cognición y autoposicionamiento ideológico. Teniendo en cuenta la cantidad de casos ( $\mathrm{N}=12$ por condición experimental), cada covariable fue introducida en modelos separados.

\footnotetext{
10 Se trata de un método similar al de Tukey, basado en la distribución del rango estudentizado y un estadístico T donde tras estimar varianzas poblacionales distintas, los grados de libertad se corrigen mediante ecuación de Welch.
} 
ANA PAMELA PAZ GARCÍA; SILVINA BRUSSINO; DANIELA ALONSO

\section{Resultados}

Tiempo de lectura

En primer lugar, se observa un efecto principal del tratamiento periodístico sesgado ideológicamente por la fuente anonimizado e identificado (VI), en el tiempo de lectura $(\mathrm{F}=7,37 ; \mathrm{p} \leq, 001)$ (Gráfico 1$)$. Los resultados de los análisis post hoc señalan que las diferencias se dan entre el grupo de "noticia LV derecha-identificada" $(M=3,62)$ y los grupos de "noticia $P 12$ izquierda-identificada" $(M=2,07)$ y "noticia $P 12$ izquierda-no identificada" $(M=2,06)(p \leq, 01)$. En este sentido, se observa que el tiempo dedicado a la lectura de la noticia es mayor cuando se trata de LV derecha-identificada.

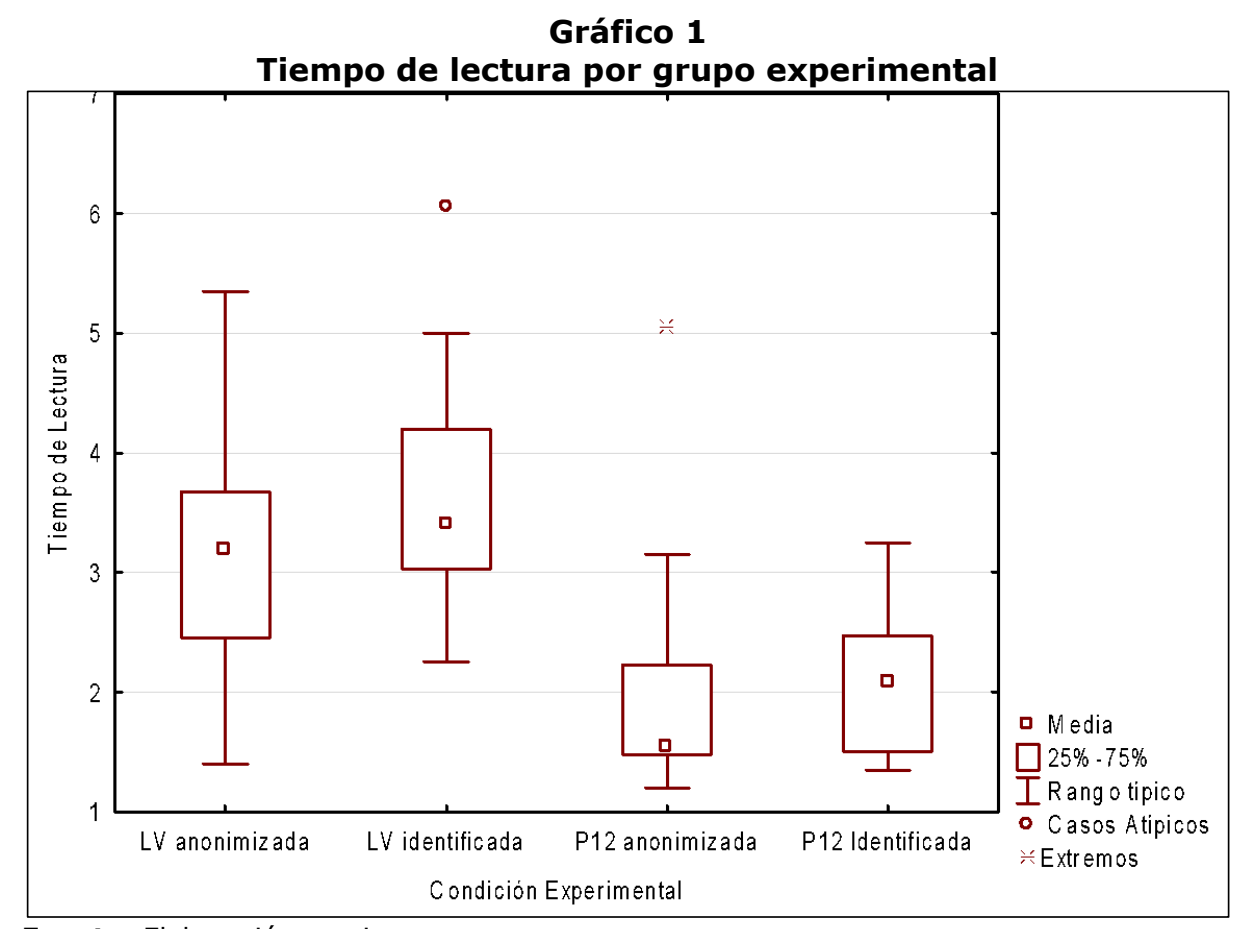

Fuente: Elaboración propia.

En un segundo momento se realizaron ANCOVAS para determinar si, además del efecto principal de la VI, se registraban efectos de interacción con las variables moduladoras auto-posicionamiento ideológico y necesidad de cognición. Al respecto, no se registraron efectos de la necesidad de cognición, pero sí del auto-posicionamiento ideológico $(F=8,16 ; p \leq, 01)$. En la Tabla 2 se expone el modelo y en el Gráfico 2 se muestran los efectos de esta interacción. Los resultados muestran que, al considerar el auto-posicionamiento ideológico como covariable, el efecto de la VI sobre el tiempo de lectura disminuye. Sin embargo, sigue siendo significativo y su potencia es mayor 
$\left(\eta^{2}=, 315\right)$ que la del auto-posicionamiento ideológico $\left(\eta^{2}=, 166\right)$, que también tuvo un efecto significativo.

Tabla 2

Influencia del auto-posicionamiento ideológico sobre la VI

\begin{tabular}{|l|c|c|c|c|c|c|}
\hline Origen & $\begin{array}{c}\text { Suma de } \\
\text { cuadrados } \\
\text { tipo III }\end{array}$ & gl & $\begin{array}{c}\text { Media } \\
\text { cuadrática }\end{array}$ & F & Sig. & $\begin{array}{c}\text { Eta al } \\
\text { cuadrado } \\
\text { parcial }\end{array}$ \\
\hline Intersección & 23,870 & 1 & 23,870 & 16,556 &, 003 &, 636 \\
\hline $\begin{array}{l}\text { Auto-posicionamiento } \\
\text { ideológico }\end{array}$ & 6,336 & 1 & 6,336 & 8,162 &, 007 &, 166 \\
\hline Condición experimental & 14,649 & 3 & 4,883 & 6,290 &, 001 &, 315 \\
\hline
\end{tabular}

Fuente: Elaboración propia.

Asimismo, como se advierte en el Gráfico 2, los participantes que se autoposicionan a la derecha tardaron más en leer $P 12$ (izquierda) que los que se autoposicionan a la izquierda, principalmente cuando la fuente no se encontraba identificada (noticia anonimizada), por su parte a los participantes de izquierda les insumió mayor tiempo la lectura de LV (derecha), aunque en este caso la brecha entre su versión identificada y anonimizada resultó menor.

Gráfico 2

Efectos del auto-posicionamiento ideológico sobre el tiempo de lectura por grupo experimental

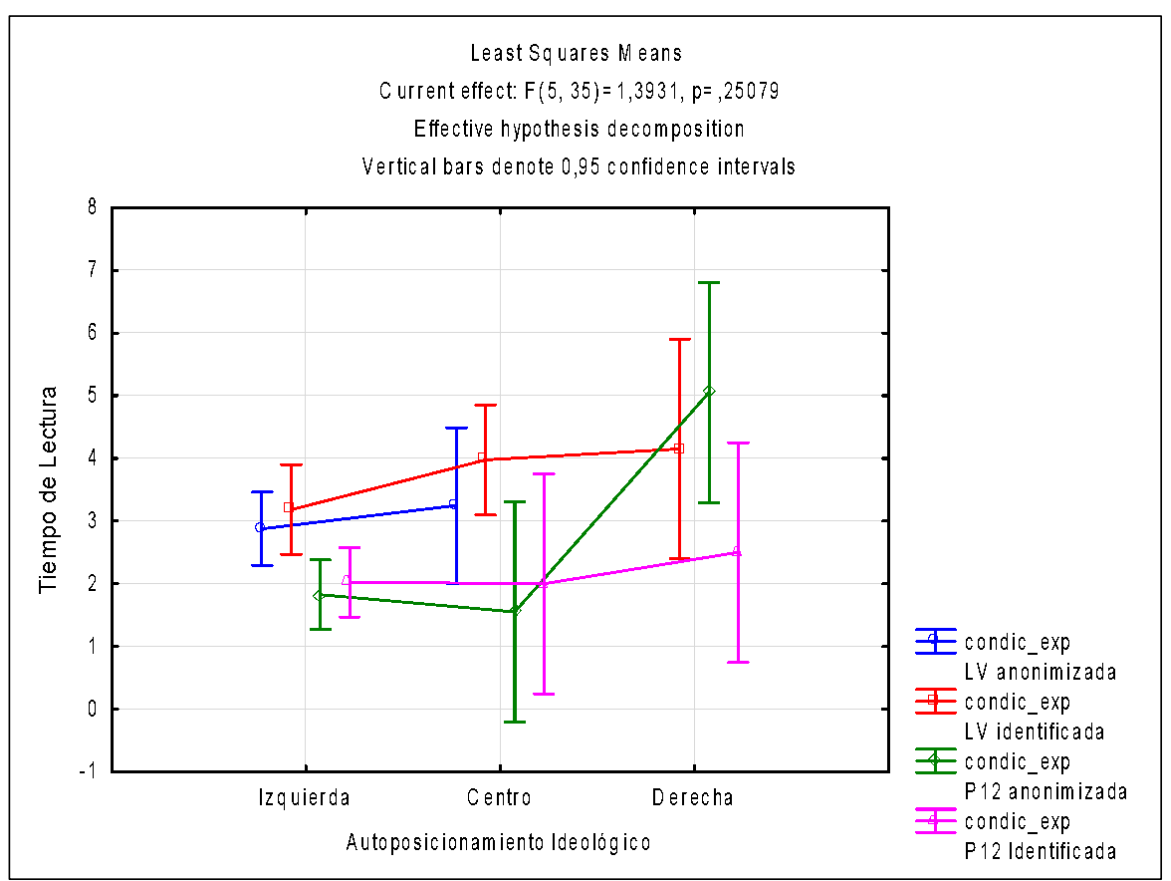

Fuente: Elaboración propia. 
ANA PAMELA PAZ GARCÍA; SILVINA BRUSSINO; DANIELA ALONSO

Nivel de comprensión y percepción de sesgo ideológico/objetividad de la noticia

No se registraron efectos principales del tratamiento periodístico sesgado ideológicamente por la fuente, identificada y anonimizada, en el nivel de comprensión de la noticia ni en la percepción de objetividad de la fuente, aunque sí se evidenció un efecto significativo sobre la percepción de sesgo ideológico ( $F=3,06 ; p \leq, 05)$ (Gráfico 3). Al respecto, y si bien los contrastes post hoc no permiten replicar las diferencias significativas entre grupos, se observa que las distancias mayores se producen entre el grupo que recibió la "noticia LV derecha-anonimizada" y el que leyó la "noticia P12 izquierda-anonimizada". De cualquier modo, en todos los casos se percibe un nivel de sesgo alto (media muestral= 4,29 en una escala de 5 puntos). Por otra parte, y en cuanto a su rol modulador, tanto la necesidad de cognición como el auto-posicionamiento ideológico no mostraron efectos de interacción con estas variables dependientes.

Gráfico 3

Percepción de sesgo por grupo experimental



Fuente: Elaboración propia.

Valoración del tratamiento informativo del tema y opinión sobre la fuente

El tratamiento periodístico sesgado ideológicamente por la fuente, identificada y anonimizada (VI), solo tuvo efecto sobre la dimensión de credibilidad de la variable 
"valoración del tratamiento informativo sobre el tema" ( $F=3,32 ; p \leq, 05)$. Los contrastes post hoc dieron cuenta de diferencias entre los grupos "noticia LV derecha-identificada" y "noticia P12 izquierda-identificada" ( $\mathrm{p} \leq, 05)$, siendo este último medio identificado como significativamente más creíble (Gráfico 4). Asimismo, este efecto principal permanece aun cuando se controlan las covariables necesidad de cognición y auto-posicionamiento ideológico, confirmando que en ningún caso éstas tienen efecto. También se controlaron estas covariables en el resto de los modelos sobre valoración del tratamiento informativo del tema, sin registrar efectos.

Gráfico 4

Dimensión de credibilidad por grupo experimental

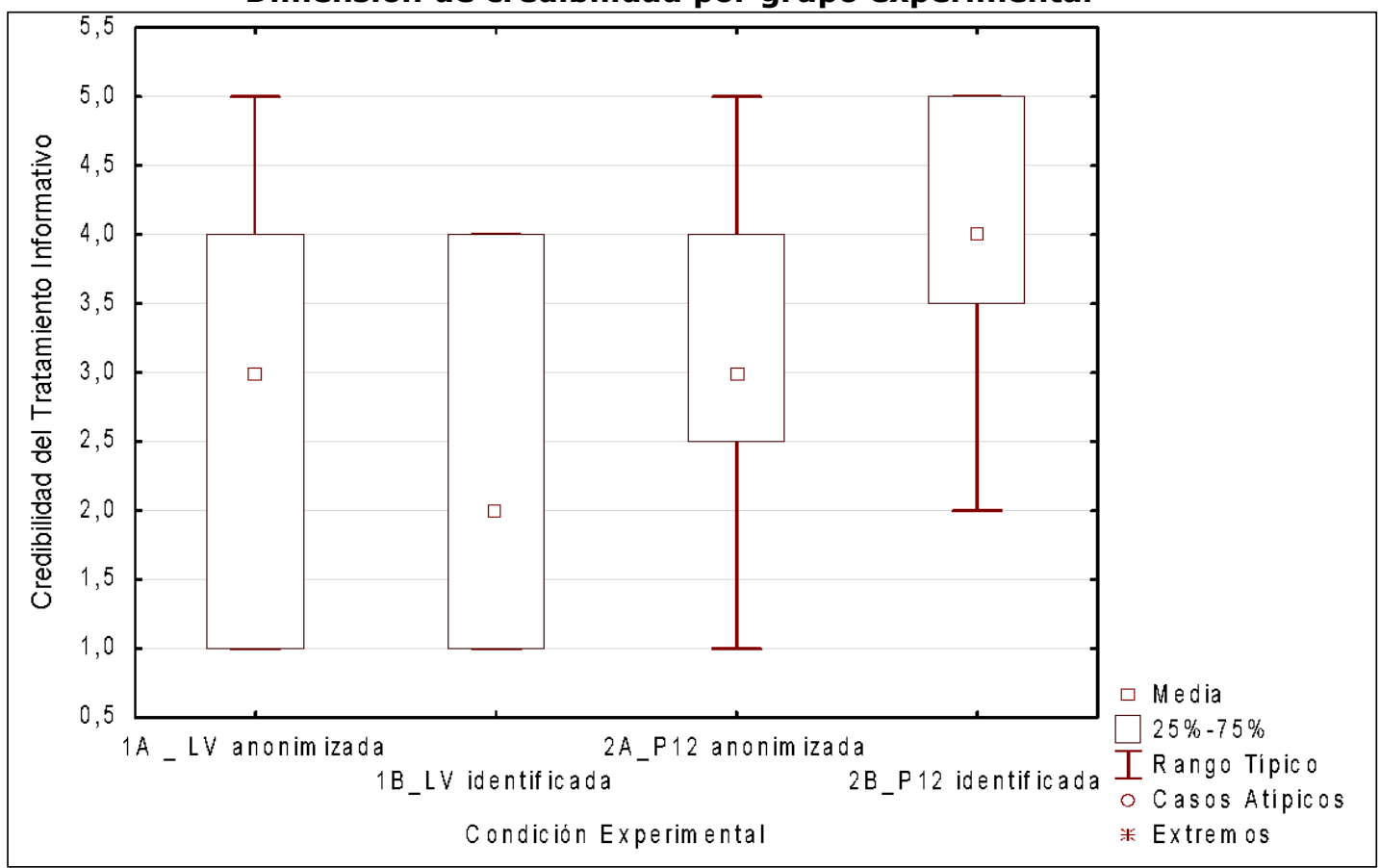

Fuente: Elaboración propia.

Finalmente, se realizaron ANOVAS para determinar el efecto del tratamiento periodístico sesgado ideológicamente por la fuente, identificada y anonimizada (VI) en la opinión sobre la fuente. Se examinaron estos efectos sobre el nivel de conocimiento y credibilidad de quien escribe, así como respecto de la confiabilidad y actualización de la noticia y su aporte informativo. Al respecto, solo se registraron efectos sobre la confiabilidad de la información brindada $(\mathrm{F}=3,5 ; \mathrm{p} \leq, 05)$ (Gráfico 5 ). Los contrastes post hoc señalan que las diferencias significativas se produjeron entre los grupos de "noticia LV derecha-anonimizada" y "noticia P12 izquierda-identificada". 
Gráfico 5

Dimensión de confiabilidad por grupo experimental

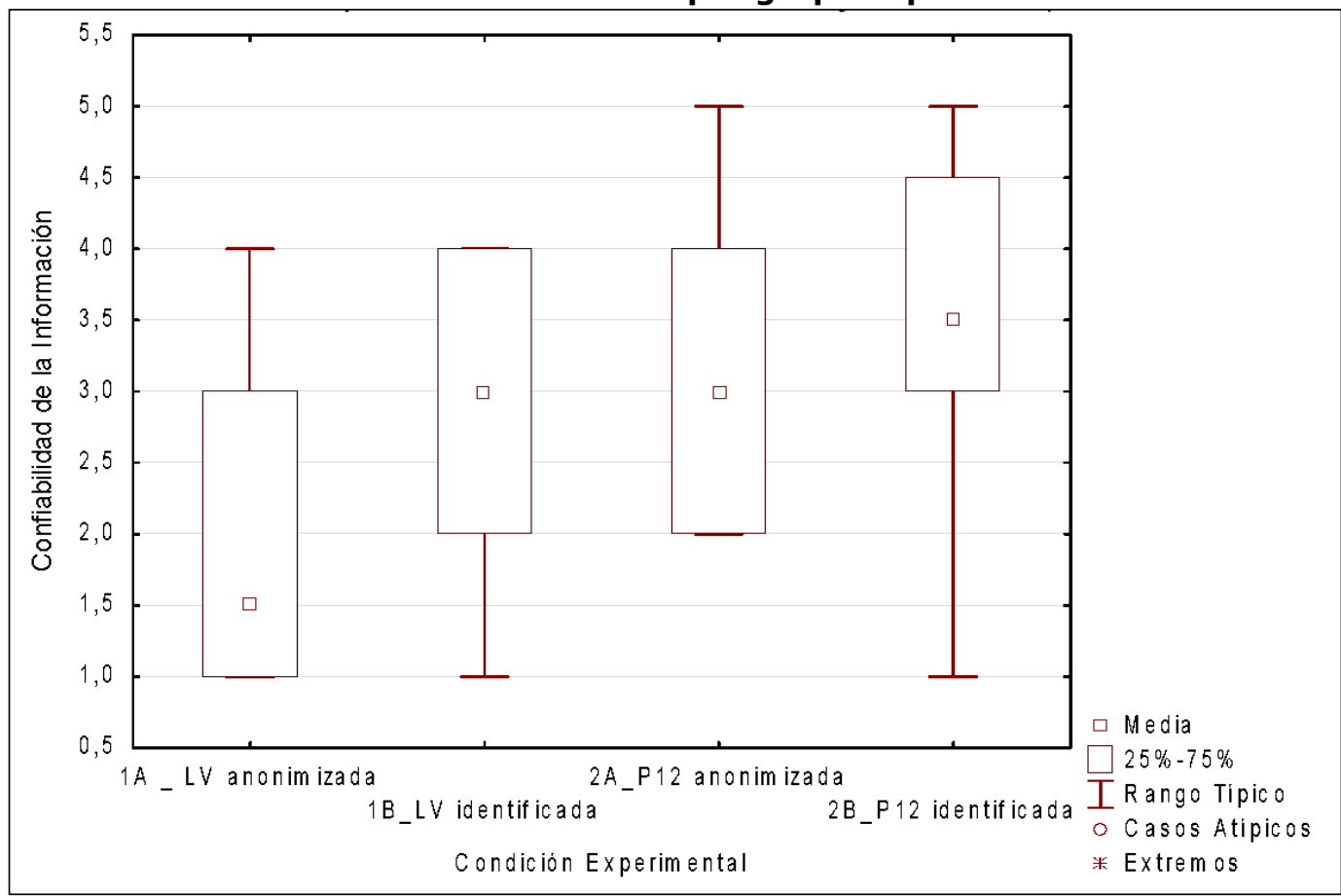

Fuente: Elaboración propia.

Además, se estimaron ANCOVAS para examinar el rol de las covariables, observando que la dimensión negativa de la escala de necesidad de cognición tenía un efecto sobre la confiabilidad de la fuente. En la Tabla 3 se exponen los datos correspondientes al modelo, donde la introducción de la necesidad de cognición negativa (NFC) contribuye al efecto de la VI sobre la confiabilidad de la información ( $F=5,809$; $\mathrm{p} \leq, 01)$, en tanto dimensión de la variable opinión sobre la fuente. Ambas muestran efectos significativos sobre la VD y una potencia explicativa similar, siendo relativamente más alta la de la condición experimental $\left(\eta^{2}=, 288\right)$ respecto de la covariable NFC dimensión negativa $\left(\eta^{2}=, 200\right)$. 
Tabla 3

Efectos de VI y covariables en la opinión sobre la fuente (dimensión de confiabilidad)

\begin{tabular}{|l|c|c|c|c|c|c|}
\hline Origen & $\begin{array}{c}\text { Suma de } \\
\text { cuadrados } \\
\text { tipo III }\end{array}$ & gl & $\begin{array}{c}\text { Media } \\
\text { cuadrática }\end{array}$ & F & Sig. & $\begin{array}{c}\text { Eta al } \\
\text { cuadrado } \\
\text { parcial }\end{array}$ \\
\hline Modelo corregido & $27,364^{\mathrm{a}}$ & 4 & 6,841 & 5,889 &, 001 &, 354 \\
\hline Intersección & 4,967 & 1 & 4,967 & 4,276 &, 045 &, 090 \\
\hline NFC dimensión negativa & 12,468 & 1 & 12,468 & 10,733 &, 002 &, 200 \\
\hline Condición experimental & 20,242 & 3 & 6,747 & 5,809 &, 002 &, 288 \\
\hline Error & 49,949 & 43 & 1,162 & & & \\
\hline Total & 457,000 & 48 & & & & \\
\hline Total corregida & 77,313 & 47 & & & & \\
\hline a. R cuadrado =,354 (R cuadrado corregida & ,294)
\end{tabular}

Fuente: Elaboración propia.

Además, se controlaron los efectos de las covariables en todos los modelos de opinión sobre la fuente, encontrando un efecto de la dimensión negativa de la necesidad de cognición en la valoración de los participantes acerca del conocimiento evidenciado por la fuente (Tabla 4) y su capacidad para ofrecer información actualizada (Tabla 5). En el primer caso, la introducción de la necesidad de cognición negativa aporta al poder explicativo de la VI, que no resultó significativo en el ANOVA realizado. Así, el tratamiento periodístico sesgado ideológicamente funciona como principal predictor $\left(\eta^{2}=, 235\right)$, mientras la NFC en su dimensión negativa también muestra un efecto significativo $\left(\eta^{2}=183\right)$ de menor intensidad.

Tabla 4

Efectos de VI y covariables en la opinión sobre la fuente (dimensión de conocimiento)

\begin{tabular}{|l|c|c|c|c|c|c|}
\hline Origen & $\begin{array}{c}\text { Suma de } \\
\text { cuadrados } \\
\text { tipo III }\end{array}$ & gl & $\begin{array}{c}\text { Media } \\
\text { cuadrática }\end{array}$ & F & Sig. & $\begin{array}{c}\text { Eta al } \\
\text { cuadrado } \\
\text { parcial }\end{array}$ \\
\hline Modelo corregido & $21,779^{a}$ & 4 & 5,445 & 4,855 &, 003 &, 311 \\
\hline Intersección & 8,066 & 1 & 8,066 & 7,193 &, 010 &, 143 \\
\hline NFC dimensión negativa & 10,779 & 1 & 10,779 & 9,612 &, 003 &, 183 \\
\hline Condición experimental & 14,786 & 3 & 4,929 & 4,395 &, 009 &, 235 \\
\hline Error & 48,221 & 43 & 1,121 & & & \\
\hline Total & 502,000 & 48 & & & & \\
\hline Total corregida & 70,000 & 47 & & & & \\
\hline a. R cuadrado $=, 311$ (R cuadrado corregida $=, 247)$ &
\end{tabular}

Fuente: Elaboración propia. 
Para el caso del efecto de la NFC negativa sobre la percepción de actualización de la fuente (Tabla 5 ), solo la covariable registra un efecto significativo $(F=4,89 ; p \leq, 05)$ aunque su potencia explicativa resulta pequeña $\left(\eta^{2}=, 102\right)$. La VI no muestra una influencia significativa entre los participantes respecto de esta dimensión de la opinión sobre la fuente.

\section{Tabla 5}

Efectos de VI y covariables en la opinión sobre la fuente (dimensión de actualización)

\begin{tabular}{|c|c|c|c|c|c|c|}
\hline Origen & $\begin{array}{c}\text { Suma de } \\
\text { cuadrados } \\
\text { tipo III }\end{array}$ & gl & $\begin{array}{c}\text { Media } \\
\text { cuadrática }\end{array}$ & $\mathbf{F}$ & Sig. & $\begin{array}{c}\text { Eta al } \\
\text { cuadrado } \\
\text { parcial }\end{array}$ \\
\hline Modelo corregido & $11,091^{\mathrm{a}}$ & 4 & 2,773 & 1,982 &, 114 & 156 \\
\hline Intersección & 13,904 & 1 & 13,904 & 9,938 & ,003 & 188 \\
\hline $\begin{array}{l}\text { NFC - dimensión } \\
\text { negativa }\end{array}$ & 6,841 & 1 & 6,841 & 4,890 & ,032 & 102 \\
\hline Condición experimental & 6,306 & 3 & 2,102 & 1,502 &, 227 & ,095 \\
\hline Error & 60,159 & 43 & 1,399 & & & \\
\hline Total & 540,000 & 48 & & & & \\
\hline Total corregida & 71,250 & 47 & & & & \\
\hline
\end{tabular}

Fuente: Elaboración propia.

\section{Conclusiones}

En primer lugar y desde una perspectiva general, se destaca el aporte de las técnicas experimentales a la comprensión del consumo mediático-informativo en términos ideológicos, en línea con el paradigma sobre los efectos negociados de los medios masivos. Al respecto, la efectividad político-persuasiva de las comunicaciones masivas ya no se relacionaría de manera directa con el nivel de exposición de las audiencias, sino con el grado de consistencia entre ésta y otras conductas desplegadas en línea con disposiciones actitudinales propias y ajenas. Así el impacto de la ideología y algunas de sus variantes actitudinales centrales (auto-posicionamiento, etiquetas y sesgo percibido), se analizaron aquí siguiendo una observación metodológica contemporánea central como es la identificación de temas de agenda o issues políticos coyunturales (Knobloch-Westerwick y Meng, 2009) - en lugar de preferencias partidarias -, en tanto clave de estudio del fenómeno de objetividad/sesgo en los contenidos mediáticos. Si bien, como señalan Gerber, Karlan y Bergan (2009), la posibilidad de generalizar los hallazgos empíricos ostensibles bajo esta lógica depende de características específicas de la situación experimental "tales como el contexto político, la elección de los sujetos, la intensidad del tratamiento, la duración del estudio, el ritmo del estudio y la elección de las fuentes mediáticas" (p. 48), en la presente investigación las relaciones de causa-efecto abordadas se vinculan directamente con condiciones coyunturales, a la vez que los resultados y 
discusiones presentados se insertan en el marco de los principales debates teóricos contemporáneos reconociendo tales condiciones de complejidad.

Por otro lado y en cuanto a las hipótesis de investigación, fue posible advertir el impacto del tratamiento periodístico sesgado ideológicamente en condiciones específicas de la experiencia de exposición tales como el tiempo de lectura, la credibilidad otorgada al tratamiento informativo del tema y la opinión sobre la fuente en su dimensión de confiabilidad (H1b). Si bien no se registraron efectos significativos de la VI sobre el nivel de comprensión noticiosa, en términos globales quiénes leyeron la noticia del diario Página 12 (de tendencia opositora) en su versión identificada valoraron su tratamiento del tema como creíble y atribuyeron mayor confiabilidad a la información brindada por la fuente, en contraste con las versiones noticiosas del diario oficialista La Voz del Interior tanto identificada como anonimizada.

Respecto de las restantes relaciones propuestas en la $\mathrm{H} 1$, se confirma un patrón de exposición pro-actitudinal (Knobloch-Westerwick y Meng, 2009) y una tendencia a un mayor tiempo de exposición ( $\mathrm{H} 1 \mathrm{a}$ ) ante fuentes no familiares, en tanto factores que avalan la vigencia de una lógica auto-referente y defensiva por parte de las audiencias ante un entorno mediático fuertemente fragmentado en términos ideológicos. Asimismo y en los términos de la $\mathrm{H} 2$, al considerar los efectos mediadores del auto-posicionamiento ideológico y la necesidad de cognición (NFC) en su dimensión negativa, estos resultados experimentales confirman las pistas de investigaciones actuales sobre selectividad mediático oposicional y construcción de la experiencia cotidiana de consumo informativo en condiciones de hostilidad mediática (Arceneaux, Johnson y Chad, 2012; Iyengar y Hahn, 2009). Así se observa cómo entre los lectores auto-posicionados hacia la derecha del espectro ideológico la noticia opositora les insumió mayor tiempo de lectura, en contraste con un comportamiento similar entre participantes auto-ubicados hacia la izquierda respecto de la noticia oficialista (H2). En sintonía con estos hallazgos, en estudios locales y contemporáneos sobre población general (Brussino et al., 2011; Paz García y Brussino, 2014, 2015) así como en estudios ibero-latinoamericanos sobre poblaciones juveniles (López Sáez y Martínez Rubio, 2005; Merolla, Stephenson y Zechmeister, 2007), se destaca una relación significativa entre el auto-posicionamiento ideológico y el consumo mediático-informativo, coincidente con estas nuevas evidencias sobre la tesis de la disonancia cognitiva que advierten en la ideología política un método heurístico anticipatorio de las decisiones de exposición de las audiencias. Se advierte además un aporte de la NFC al efecto de la VI restringido a la dimensión negativa de la escala, encontrando que los participantes que tendieron a ubicarse en una posición conservadora o de derecha y registraron altas puntuaciones en dicha dimensión valoraron como menos confiable la fuente noticiosa. Dentro de una perspectiva condicional de los efectos de los medios y sus mensajes (Valkenburg, Peter y Walther, 2016), se verifica así el papel moderador y dinámico de las actitudes de las audiencias en el marco de sus respectivos modos de procesamiento cognitivo de la información política. 
Finalmente y retomando la importancia de las condiciones ambientales en que se producen los procesos estudiados, cabe destacar el papel orientador y defensivo desempeñado por los comportamientos selectivos de las audiencias ante informaciones cargadas de intencionalidades políticas en el marco de ambientes polarizantes; y al respecto, surge la pregunta por cierto bloqueo cognitivo-democrático que el cierre sobre contenidos y fuentes exclusivamente pro-actitudinales podría significar. Considerando al conflicto político como variable de distinción y potenciamiento de posturas ideológicas en sociedades hipermediatizadas, desde la perspectiva de la presente investigación son las actitudes hacia la información política el espacio del comportamiento donde se materializa la influencia de etiquetas, pistas y frames ideológicos bajo procesos de razonamiento selectivo motivado. Dentro de estos procesos se destaca la tendencia a la percepción de nueva información como confirmatoria (Druckman, Peterson y Slothuus, 2013; Feldman, 2008, 2011), incrementando la confianza en opiniones previas. En el marco de la H1b, esta situación de refuerzo de la exposición selectiva se observa en todos los grupos experimentales: mientras entre los lectores de La Voz del Interior la confiabilidad aumenta con la noticia identificada como perteneciente al medio, en la lectura de Página 12, si bien la confiabilidad atribuida es mayor para los dos tipos de versiones (anónima e identificada), ésta aumenta notablemente también con la nota identificada. Asimismo, se advierten niveles base de confianza y credibilidad notoriamente más altos en el caso de la noticia anonimizada de Página 12, en contraste con el mismo tipo de versión de La Voz del Interior, situación entendible en el marco de una muestra mayoritariamente posicionada hacia la izquierda o de tendencia progresista donde el diario Página 12 con frecuencia es etiquetado como medio coincidente con dicha postura. Al respecto y como se ha señalado, se verifica cierto efecto circular de familiaridad ideológica que operaría reforzando el procesamiento cognitivo negativo de fuente discordante con la propia posición, efecto descripto por Feldman $(2008,2011)$ para el caso de las "noticias opinadas".

Cabe destacar que si como indica la literatura, los efectos de confianza y credibilidad atribuidos a las fuentes mediáticas desde su base ideológica se desplazan hacia los contenidos, en el marco de las evidencias limitadas aportadas por la presente investigación, cabe reflexionar si esta dinámica heurística que ciertamente recibe los efectos de la polarización de entorno político-comunicativo, también guarda efectos sobre el mismo a partir de las preferencias que de este modo se ven reforzadas. Al respecto, por último se advierte una línea comunicante entre la verificación parcial de las $\mathrm{H} 1 \mathrm{a}$ y $\mathrm{H} 1 \mathrm{~b}$ : mientras en línea con hallazgos de Gerber, Karlan y Bergan (2009) no se verifica un efecto directo del tratamiento sesgado en la asimilación de los contenidos informativos (comprensión noticiosa), en diálogo con Feldman (2011) se verifica una conexión entre la percepción de sesgo, la valoración del tratamiento informativo del tema y la opinión sobre la fuente que covaría en función del auto-posicionamiento ideológico de las audiencias. Así, en paralelo a la influencia del tratamiento periodístico sesgado ideológicamente sobre la credibilidad de los participantes en torno al tratamiento del tema, se destacan los efectos 
de refuerzo evidenciados por la necesidad de cognición negativa en su opinión sobre la fuente, en particular en lo que respecta a su confiabilidad, conocimiento y capacidad para ofrecer información actualizada. Aquí cobra particular relevancia la observación de Feldman $(2008,2011)$ en torno a la existencia de marcas partidarias en las valoraciones de las audiencias sobre los contenidos, junto a la evidencia de huellas del receptor en los sesgos atribuidos a las fuentes, encontrando que en ambos casos opera la ideología política como sustrato significativo. Tanto la subjetividad política del receptor como los marcos y etiquetas ideológicas pre-existentes a él reciben influencia contextual y operan sobre fuentes y contenidos informativos, abonando efectos de resonancia no solo a nivel del mercado político-mediático (Iyengar y Hahn, 2009) sino también a nivel interno e intersubjetivo. Así, se advierte un movimiento de ida y vuelta entre procesos atributivos y asimilativos desplegados por las audiencias en torno a las noticias políticas. En futuras investigaciones se impone la necesidad de profundizar tanto las características discursivas de las atribuciones de objetividad y sesgo ideológico, como las claves de atención/recordación en torno al tratamiento periodístico de las noticias políticas, considerando ambos elementos en el contexto específico de las razones o motivos que estructuran las decisiones y preferencias cotidianas de consumo mediático-informativo de las audiencias.

\section{Referências bibliográficas}

ARCENEAUX, K.; JOHnSON, M.; ChAD, M. "Polarized political communication, oppositional media hostility, and selective exposure". The Journal of Politics, vol. 74, no 1, p. 174-186, 2012.

BACHL, M. "Selective exposure and hostile media perceptions during election campaigns". International Journal of Public Opinion Research, vol. 1, no 12, maio 2016.

BalÁn, M. "Polarización y medios a 30 años de democracia". Revista Saap, vol. 7, no 2, p. 473-481, nov. 2013.

Balluerka, N.; Vergara, A. Diseños de investigación experimental en psicología. Madrid: Prentice Hall, 2002.

BARnidge, M., et al. "Politically motivated selective exposure and perceived Media Bias". Communication Research, vol. 47, no 1, p. 82-103, 2020. Disponible en: <https://doi.org/10.1177/0093650217713066>. Acceso en: jun. 2020.

Barón López, F. J.; Téllez Montiel, F. "Apuntes de bioestadística". Cátedra de Bioestadística, Tercer Ciclo en Ciencias de la Salud y Medicina, Departamento de Matemática Aplicada, Universidad de Málaga, 2004. Disponible en:

<http://www.bioestadistica.uma.es/baron/apuntes/ficheros/cap01.pdf>. Acceso en: 16 dic. 2019.

BIROLI, F.; Miguel, L. F. "Orgulho e preconceito: a 'objetividade' como mediadora entre o jornalismo e seu público". Opinião Pública, Campinas, vol. 18, nº 1, p. 22-43, jun. 2012.

BRUSSINo, S., et al. "Ideología política y prácticas mediatizadas de consumo informativo". Revista Debates, vol. 5, no 2, p. 13-40, jul.-dic. 2011. 
ANA PAMELA PAZ GARCÍA; SILVINA BRUSSINO; DANIELA ALONSO

Di PaOlo, B. I. "Clarín y Página/12 en el debate sobre la Ley de Servicios de Comunicación Audiovisual". La Trama de la Comunicación, vol. 21, no 2, p. 29-49, jul.-dic. 2017.

Druckman, J.; Peterson, E.; SlothuUs, R. "How elite partisan polarization affects public opinion formation". American Political Science Review, vol. 107, no 1, p. 57-79, jan. 2013.

DRUCKMAN, J., et al. "The growth and development of experimental research in political science". American Political Science Review, vol. 4, p. 627-635, nov. 2006.

FALCES, C., et al. "Validación de la escala de necesidad de cognición y su aplicación al estudio del cambio de actitudes". Psicothema, vol. 13, no 4, p. 622-628, 2001.

FARA, C. "Comunicación política en América Latina: tendencias, factores y problemas prácticos", Diálogo Político, vol. XXII, no 1, p. 79-99, 2005.

FELDMAN, L. "The tension between receiver bias and journalist bias in opinionated news: a study of information processing". Trabajo presentado en NCA 94th Annual Convention, TBA, San Diego, p. 147, oct.-nov. 2008.

. "Partisan differences in opinionated news perceptions: a test of the hostile media effect". Political Behavior, vol. 33, no 3, p. 407-432, sep. 2011.

FLAX, R. "Cristina Kirchner y los medios gráficos: el rol de los jóvenes militantes". Lengua y Habla, vol. 17, p. $67-87,2013$.

Gerber, A.; KARLAN, D.; Bergan, D. "Does the media matter? A field experiment measuring the effect of newspapers on voting behaviour and political opinions". Journal of Applied Economics, vol. 1, no 2, p. 35-52, 2009.

GoMES, W. "Por que a mídia é tão parcial e adversária da minha posição? A hipótese da hostile media perception". Revista Compolítica, vol. 6, no 1, p. 7-26, 2016.

Gunther, A. C. Hostile media effect. In: Rössler, P.; Hoffner, C. A.; VAn Zoonen, L. (eds.). The International Encyclopedia of Media Effects. New Jersey: John Wiley \& Sons Inc., 2017.

Gunther, A. C.; ChIA, S. C. "Predicting pluralistic ignorance: the Hostile Media Perception and its consequences". Journalism \& Mass Communication Quarterly, vol. 78, no 4, p. 688-701, 2001.

INGRASSIA, P. "8N y $18 \mathrm{~F}$ en Clarín y Página 12. Estudio sobre la construcción informativa de dos marchas de alcance nacional". Question - Revista Especializada en Periodismo y Comunicación, vol. 1 , no 51 , jul.-sep. 2016.

IYENGAR, S.; HAHN, K. S. "Red media, blue media: evidence of ideological selectivity in media use". Journal of Communication, vol. 59, p. 19-39, 2009.

JoRge, J. E.; MiRó, E. M. "Medios de comunicación, democracia y cultura política". Question - Revista Especializada en Periodismo y Comunicación, vol. 1, no 30, abr.-jun. 2011.

Knobloch, S.; Dillman Carpentier, F.; Zillmann, D. "Effects of salience dimensions of informational utility on selective exposure to online news". Journalism \& Mass Communication Quarterly, vol. 80, no 1 , p. 91-108, 2003.

KNOBLOCH, S., et al. "Imagery effects on the selective reading of internet newsmagazines". Communication Research, vol. 30, no 1, p. 3-29, 2003.

KNOBLOCH-WeSTERWICK, S.; MENG, J. "Looking the other way. Selective exposure to attitude-consistent and counterattitudinal political information". Communication Research, vol. 36, no 3, p. 426-448, 2009. 
EFECTOS DEL TRATAMIENTO PERIODÍSTICO SESGADO IDEOLÓGICAMENTE EN EL PROCESAMIENTO COGNITIVO DE INFORMACIÓN POLÍTICA

Liepins, K.; Porath, W.; Puente, S. "Cómo mejorar la comprensión de las noticias televisivas". Comunicación y Sociedad, vol. XXII, no 2, p. 49-76, jan. 2010.

LóPez SÁEZ, M.; MARTínez Rubio, J. "¿influyeron los procesos de comunicación sobre los sucesos del 11-M en las votaciones del 14-M? La percepción de los jóvenes en función de su ideología política". Revista de Psicología Social, vol. 20, no 3, p. 351-367, 2005.

MATthes, J. "The affective underpinnings of Hostile Media Perceptions: exploring the distinct effects of affective and cognitive involvement". Communication Research, p. 1-28, sep. 2011.

McDermott, R. "Experimental methods in political science". Annual Review of Political Science, vol. 5, p. 31-61, jun. 2002.

Merolla, J.; StePhenson, L.; ZeChMeister, E. "La aplicación de los métodos experimentales en el estudio de los atajos informativos en México". Política y Gobierno, vol. XIV, nº 1, p. 117-142, 2007.

MORTON, R.; Williams, K. Experimentation in political science. In: Box-Steffensmeier, J.; CollieR, D. ; BrADY, H. (eds.). The Oxford Handbook of Political Methodology. Oxford: Oxford University Press, 2006.

Paz García, A. P.; Brussino, S. "Perfiles ideológicos de consumo mediático de información política en Córdoba-Argentina". Anagramas, vol. 13, no 24, p. 95-118, 2014.

"Consumo juvenil de información política. Análisis estructural y reticular de las preferencias mediáticas de universitarios cordobeses (Argentina, 2012)". Redes - Revista Hispana para el Análisis de Redes Sociales, vol. 26, no 2, p. 171-205, 2015.

PAz García, P.; Sgró RuATA, C.; GuzmÁn, V. "Sujetos y contextos de la comunicación mediática en América Latina. Algunas consideraciones sobre su democratización". Espacio Abierto - Cuaderno Venezolano de Sociología, vol. 22, no 3, p. 393-412, jul. 2013.

PETTY, R.; CACIOPPO, J. "The elaboration likelihood model of persuasion". Advances in Experimental Social Psychology, vol. 19, p. 123-205, 1986.

SCHIEFELE, U. The influence of topic interest, prior knowledge, and cognitive capabilities on text comprehension. In: Pieter, J. M.; BReuer, K. ; Simons, P. R. J. (eds.). Learning environments. Berlin: Springer, 1990.

SCHIEfELE, U.; KRAPP, A. "Topic interest and free recall of expository text". Learning and Individual Differences, vol. 8, no 2, p. 141-160, 1996.

SHAH, D. V., et al. "Revisiting the Communication Mediation Model for a new political communication ecology". Human Communication Research, p. 1-14, jul. 2017.

TURGEON, M.; RENNó, L. "Informação política e atitudes sobre gastos governamentais e impostos no Brasil: evidências a partir de um experimento de opinião pública". Opinião Pública, Campinas, vol. $16, n^{\circ} 1$, p. 143-159, jun. 2010.

VAGGIONE, J.; BRUSSINO, S. "El apartidismo y el apolitismo. Un análisis a partir de la sensación de falta de poder". Anuarios CIJS, p. 307-320, 1997.

Valkenburg, P. M.; Peter, J.; Walther, J. B. "Media effects: theory and research". Annual Review of Psychology, vol. 67, p. 315-338, jan. 2016.

VAllone, R. P.; Ross, L.; LePper, M. R. "The hostile media phenomenon: biased perception and perceptions of media bias in coverage of the Beirut massacre". Journal of Personality and Social Psychology, vol. 43, no 3, p. 577-585, 1985. 


\begin{abstract}
Effects of ideologically biased journalistic treatment in cognitive processing of political information. An experimental approach

Recognizing the conditions of polarization of the current media market, salient features of the cognitive processing of textual political information of conjunctural importance (real press news from contrasting ideological sources) are addressed. By applying an inter-subject experimental design of random groups (with an independent variable that assumes four levels) without a control group, the effects of ideologically biased journalistic treatment on information processing of local audiences are analyzed. Likewise, the modulating role of variables as 'need for cognition' and 'ideological self-placement' is valued. Among the main results, a pro-attitudinal pattern and a longer exposure time to non-family sources are confirmed, together with a connection between perception of bias, assessment of the topic and opinion about the source, variable by according to participants' self-positioning, among other factors that show a selective logic of self-referential and defensive consumption.
\end{abstract}

Keywords: political information; media selectivity; political ideology; consumption; Argentina

\title{
Resumo
}

Efeitos do tratamento jornalístico ideologicamente tendencioso no processamento cognitivo da informação política. Uma abordagem experimental

Reconhecendo as condições de polarização do mercado atual de mídia, são abordadas características salientes do processamento cognitivo da informação política textual de importância conjuntural (notícias reais da imprensa de fontes ideológicas contrastantes). Aplicando um desenho experimental intersujeito de grupos aleatórios (com uma variável independente que assume quatro níveis) sem um grupo de controle, são analisados os efeitos do tratamento jornalístico ideologicamente tendencioso sobre o processamento de informação do público local. O papel modulador das variáveis 'necessidade de cognição' e 'autoposicionamento ideológico' também é valorizado. Entre os principais resultados, confirma-se um padrão pró-atitudinal e mais tempo de exposição a fontes não familiares, juntamente com uma conexão entre percepção de viés, avaliação do tema e opinião sobre a fonte variável em função do autoposicionamento, entre outros fatores que mostram uma lógica seletiva de consumo autorreferencial e defensivo.

Palavras-chave: informação política; seletividade midiática; ideologia política; consumo; Argentina

\section{Résumé}

Effets d'un traitement journalistique biaisé idéologiquement dans le traitement cognitif de l'information politique. Une approche expérimentale

En reconnaissant les conditions de polarisation du marché actuel des médias, les caractéristiques essentielles du traitement cognitif des informations politiques textuelles d'importance conjoncturelle (vraies nouvelles de la presse provenant de sources idéologiques contrastées) sont abordées. En appliquant une conception expérimentale inter-sujets de groupes aléatoires (avec une variable indépendante qui suppose quatre niveaux) et sans groupe témoin, les effets d'un traitement journalistique biaisé idéologiquement sur le traitement de l'information des publics locaux sont analysés. Aussi le rôle modulateur des variables 'besoin de cognition et 'auto-positionnement idéologique' est valorisé. Parmi les principaux résultats, un modèle proattitudinal et une tendance à allonger la durée d'exposition aux sources non familiales sont confirmés, ainsi qu'un lien entre la perception de biais, l'évaluation du suject et l'opinion sur la source variable en fonction de sur l'auto-positionnement de les participants, entre autres facteurs qui montrent une logique sélective de consommation auto-référentielle et défensive.

Mots-clés: information politique; sélectivité des médias; idéologie politique; consommation; Argentine

Artigo submetido à publicação em 21 de agosto de 2018. Versão final aprovada em 8 de junho de 2020.

Opinião Pública adota a licença Creative Commons CC-BY. 